\title{
The Impact of Mandatory Reporting Laws on Survivors of Intimate Partner Violence: Intersectionality, Help-Seeking and the Need for Change
}

\author{
Carrie Lippy $^{1}$ (1) $\cdot$ Selima N. Jumarali ${ }^{2} \cdot$ Nkiru A. Nnawulezi $^{2} \cdot$ Emma Peyton Williams $^{3} \cdot$ Connie Burk $^{4}$
}

Published online: 3 December 2019

(C) The Author(s) 2019

\begin{abstract}
Research illustrates the importance of help-seeking for intimate partner violence (IPV) survivors. However, mandatory reporting (MR) laws can affect help-seeking by requiring some sources of support to report survivors to formal systems. This convergent mixed methods study of 2462 survivors surveyed through the National Domestic Violence Hotline explores how MR laws impact survivors' help-seeking, the outcomes of their help-seeking, and whether their race, gender, and/or sexual orientation influenced their experiences. Findings indicated that MR laws reduce help-seeking for over a third of survivors, provider warnings about MR often reduce survivors' ability to receive the support they seek, and reports when triggered make the situation worse for most survivors. Significant differences emerged by gender identity and race/ethnicity, emphasizing unique contexts for trans and gender non-conforming survivors and survivors of color. We provide policy and practice implications given these unintended harms of MR laws for IPV survivors.
\end{abstract}

Keywords Intimate partner violence $\cdot$ Survivors $\cdot$ Domestic violence $\cdot$ Mandatory reporting $\cdot$ Help-seeking $\cdot$ Intersectionality LGBTQ $\cdot$ Race/ethnicity $\cdot$ Gender identity

\section{Introduction}

More than $36 \%$ (43.6 million) of women in the United States have experienced stalking, physical abuse and/or sexual violence by an intimate partner at some point in their lifetime (Smith et al. 2018). According to the CDC, these rates were higher for women and men of color as compared to their White counterparts (Breiding et al. 2014), and lesbian, gay, and bisexuals have as high if not higher rates of IPV compared to their heterosexual counterparts (Walters et al. 2013). The limited research on IPV for gender minorities suggests that transgender people experience IPV at higher rates than cisgender people (Langenderfer-Magruder et al. 2016). The

Carrie Lippy

clippy@nwnetwork.org

1 Northwest Network of Bi, Trans, Lesbian and Gay Survivors of Abuse, P.O. Box 18436, Seattle, WA 98118, USA

2 University of Maryland, Baltimore County, Baltimore, MD, USA

3 Oberlin College, Oberlin, OH, USA

4 Yeha:wi Cultural Services, Mother Nation, Seattle, WA, USA high rates of IPV emphasize the need for all survivors to be able to access the support they need. Evidence suggests, however, that mandatory reporting (MR) laws can affect the helpseeking strategies of survivors (Jordan and Pritchard 2018). The current study takes an intersectional approach to examine how MR affects the help-seeking behaviors of and outcomes for survivors. The following review of literature will 1) describe MR laws and their connection with IPV and 2) outline intersectionality and its importance for the current study.

\section{Mandatory Reporting}

Mandatory Reporting (MR) is a set of U.S. federal and state laws that require specific individuals to report actual or suspected abuse to a legal or governmental agency (Jordan and Pritchard 2018). These laws address multiple types of abuse and harms, including: 1) crime-related injuries deriving from use of a weapon, 2) child abuse, neglect or exploitation, 3 ) elder abuse, neglect or exploitation, and 4) domestic violence or sexual assault (Jordan and Pritchard 2018). The intentions of MR laws are to protect vulnerable populations who may otherwise be unable to protect themselves and to respond to violence that often occurs in the private sphere (Jordan and 
Pritchard 2018). MR laws vary state to state as to which of the aforementioned harms are reportable and who must report them. For example, most states specify that healthcare professional must report crime-related injuries (Durborow et al. 2013), whereas many more professionals are mandated to report child abuse and neglect, often including social workers, school officials, health and mental health professionals, child care workers, and clergy (Child Welfare Information Gateway 2016a). In fact, in 18 states and Puerto Rico, all persons above the age of 18 , regardless of profession, are required to report suspected child abuse or neglect (Child Welfare Information Gateway 2016a). In the section below, we explain the relevancy and impact of these multiple types of MR laws for IPV survivors.

Mandatory Reporting and IPV Survivors may come into contact with MR in multiple ways. First, the majority of states have MR laws requiring health care providers to report IPVrelated injuries; only four of those states allow survivors to refuse the report (Durborow et al. 2013). Second, some states include domestic violence advocates as mandatory reporters (Child Welfare Information Gateway 2016a), which can lead survivor-parents to feel at risk of being reported and under constant surveillance while at a shelter (Fauci and Goodman 2019). Third, survivors who are abused with the use of weapons and seek medical help may have their injuries reported based on MR laws for crime-related injuries (Jordan and Pritchard 2018). Fourth, most U.S. states have expansive MR laws related to child abuse or neglect that include child exposure to domestic violence (CEDV) as a form of harm to children (Child Welfare Information Gateway 2016b). Finally, in the aforementioned 18 states and Puerto Rico, MR laws turn members of survivors' informal support network (i.e., friends, family, acquaintances) into mandated reporters. Thus, survivors seeking help from both formal (e.g., healthcare providers, court systems, IPV advocates) and informal supports can potentially trigger a mandated report.

Research on the intersection of MR and IPV highlights negative consequences these laws can have for IPV survivors' help-seeking from formal sources of support. Survivors, for example, may not seek the medical care they need or withhold medically-relevant information to avoid triggering a report against themselves or their abuser (Durborow et al. 2013; Jordan and Pritchard 2018). In addition, some survivors delay or avoid seeking help for IPV from formal services, even IPVspecific services, because they fear that disclosing their experience of IPV will lead to court involvement and child removal (DeVoe and Smith 2003).

A review of the literature confirms survivors' fears; studies show that child welfare cases related to DV are more likely to result in child removal and out-of-home placement compared to cases related to other issues (Ogbonnaya and Pohle 2013). Survivors who have called the police to remove their abuser from the home have had their child taken away or were forced to plead guilty to child neglect in court (DeVoe and Smith 2003). Black survivors are disproportionately impacted based on overrepresentation of Black children in the child welfare system (Girardet et al. 2016). Mothers of color are also more likely to be referred to CPS for IPV-related concerns relative to White mothers who are more likely to be referred for mental health and other issues (Dosanjh et al. 2008). A recent study showed that even IPV advocates note CPS' systemic and negative biases against mothers of color surviving violence (Goodman et al. 2019).

Even though all adults are mandated reporters in over a third of U.S. states, we identified no prior research examining the impact of MR laws on survivors' help-seeking from informal supports. Informal networks are very important for survivors: survivors turn first and most often to friends and family for support for IPV (Sylaska and Edwards 2014; Trotter and Allen 2009). This is especially true for survivors of marginalized backgrounds because of the disparate treatment they can receive from formal sources of support, such as the court systems (Calton et al. 2016; Deutsch et al. 2017), social service agencies (Kanuha 2005), and law enforcement (Richie 2012; Hirschel et al. 2007).

Research on survivors' perspectives of MR laws is mixed. Much of the research in this area dates from the late 1990s and early 2000s and shows that whereas some survivors are optimistic about supports resulting from MR, others feared that a report would increase retaliation from their partner (see Coulter and Chez 1997; Gielen et al. 2000). More recent research generates similar findings of ambivalence about MR laws. One study illustrates survivors' general support for the law while remaining split about whether survivors should be able to prevent a report and whether the report could increase the likelihood of abuse (Antle et al. 2010). Another study demonstrates that survivors are against mandating medical reporting until system-level changes are made that enhance survivors' safety (Sullivan and Hagen 2005). One recent study shows that although only a small percentage of survivors opposed mandatory reporting outright, nearly two in five were less likely to seek help from a domestic violence shelter had they known they would be reported (Jordan and Pritchard 2018). Survivors' racial and language backgrounds may influence their perceptions of MR, particularly because survivors' cultural backgrounds influence their disclosure of IPV (Ahrens et al. 2010). That is, cultural values such as prioritizing family wellbeing over one's own, taboos against discussing sex and abuse, and traditional beliefs about marriage make it difficult to identify and disclose abuse (Ahrens et al. 2010).

\section{Intersectionality}

Understanding the full complexity of MR's impact on IPV survivors requires the utilization of an intersectional 
framework. Intersectionality is a structural framework and praxis that calls attention to the simultaneous and compounded impacts of oppression across multiple dimensions of identity (Collins and Bilge 2016). It highlights the need for a structural analysis of hierarchies created by systems of power and privilege in order to accurately describe the experiences of all people and especially those multiply marginalized (Collins and Bilge 2016). A structural analysis of the impact of MR on IPV survivors requires consideration of the multiple systems involved in the experiences of IPV survivors (e.g., criminal legal, housing, healthcare, immigration) and a recognition that survivors navigate those systems differently based on the intersection of multiple dimensions of their identities.

Additionally, intersectionality challenges some of the homogenizing tendencies of research by moving away from monolithic categories and identities - like "IPV survivors"and examining potential subgroup differences (Dill and Zambrana 2009). This allows the development of a more nuanced and contextualized understanding of survivors' experiences. Little research to date on MR's impact on survivors examines within group differences on the basis of race/ethnicity, sexual orientation, or gender identity.

\section{Current Study}

Taken together, Mandatory Reporting (MR) laws influence survivors' ability to seek and receive support. Studies point broadly to the inhibiting effect of MR laws on survivors' helpseeking from certain formal supports; however, none examine the effects on help-seeking broadly across multiple sources of formal and informal supports. Other studies highlight the negative impact of law enforcement and child welfare systems for survivors, but they do not explore survivors' experiences with these systems in the context of MR laws specifically. Further, we found very few studies that considered demographic group differences in their analysis of the impact of MR on IPV survivors. Given the disproportionate impact that MR laws may have on communities of color and LGBTQ communities, it is especially critical to understand if and how these laws differentially affect survivors. The current study examined the influence of MR laws on the help-seeking behaviors of survivors of violence. Using a convergent mixed methods design, we sought to answer the following: (1) how does mandatory reporting affect help-seeking behaviors and the outcomes of these behaviors for IPV survivors? (2) How does this vary across race, gender, sexual orientation and their intersections?

\section{Method}

This study utilized a convergent mixed methods approach. We simultaneously collected quantitative and qualitative data, analyzed them separately, and then compared results from each to identify similarities and discrepancies in the findings (Creswell 2014).

\section{Participants}

The analytic sample comes from a larger preexisting, anonymous dataset collected in 2015 by the National LGBTQ Domestic Violence Capacity Building Learning Center (CBLC) in partnership with the National Domestic Violence Hotline (the Hotline). This larger dataset consisted of 3616 domestic violence survivors and help-seekers who agreed to participate in a brief, online survey while waiting to be connected with an advocate through the Hotline's chat services during a six-week period in the spring of 2015 (Lippy et al. 2016). The response rate for the overall sample was $39.7 \%$, which was roughly double the response rate for prior surveys through the Hotline chat function. Subjects who agreed to participate in the survey were slightly older and more likely to be female than those who did not agree to participate; otherwise, no other systematic differences emerged by willingness to participate. We obtained approval from the Institutional Review Board (IRB) for secondary data analysis.

We excluded from analysis survivors under the age of 18 to reduce the risk that participants described experiences of seeking help for violence other than IPV (e.g., child abuse). We also excluded participants who reached out to the Hotline to seek help on behalf of someone else. The final sample included 2462 survivors, of whom 57\% were White, 16\% Latinx, $14 \%$ Black, $7 \%$ Asian, and 6\% Multiracial. Participant ages varied from 18 to 74 years old $(M=31)$, with $80 \%$ of the sample under 40 years old. The majority of the sample identified as non-transgender women (88\%), with $11 \%$ identifying as non-transgender men and $2 \%$ as transgender or gender nonconforming (TGNC). To identify potential differences in experiences for TGNC survivors, we analyzed them as a separate category from men and women. We use the terms "women-" and "men-" to acknowledge that these categories are not complete without including trans women and trans men. Finally, the sample mostly identified as heterosexual (85\%), while $8 \%$ identified as bisexual, $4 \%$ as gay or lesbian, and $4 \%$ as sexually fluid, which included survivors who identified as queer, pansexual, questioning, and those who selected multiple sexual orientation options. Table 1 provides a summary of participant demographic information. Because we did not collect information on participants' preferred pronouns, we use the gender-neutral singular pronoun "they/them" to refer to individual participants in the manuscript.

\section{Materials and Procedure}

Measure The CBLC, in partnership with the Hotline, developed the online survey to explore how MR laws and practices 
Table 1 Analytic Sample Descriptives $(n=2462)$

\begin{tabular}{lll}
\hline & $\#$ & $\%$ \\
\hline Gender $(n=2448)$ & & \\
Women- & 2145 & $87.6 \%$ \\
Men- & 265 & $10.8 \%$ \\
Trans \& Gender Non-Conforming & 38 & $1.6 \%$ \\
Sexual Orientation ( $n=2417)$ & & \\
Heterosexual & 2037 & $84.3 \%$ \\
Bisexual & 188 & $7.8 \%$ \\
Gay/Lesbian & 92 & $3.8 \%$ \\
Sexually fluid & 100 & $4.1 \%$ \\
Race/Ethnicity $(n=2317)$ & & \\
White/Caucasian & 1317 & $57.1 \%$ \\
Latino/a/ Hispanic & 366 & $15.9 \%$ \\
Black/ African American & 324 & $14.0 \%$ \\
Asian/ Asian American & 164 & $7.1 \%$ \\
Multi-racial/ Mixed race & 136 & $5.9 \%$ \\
\hline
\end{tabular}

influenced DV survivors' help-seeking. We asked about survivors' direct experiences with MR using three main questions: 1) "Have you ever not asked someone for help because you were afraid the person would be legally required to report what you shared to an official or authority figure?", 2) "Has anyone that you asked for help warned you that they would be legally required to report what you shared with them to an official or authority figure?" and 3) "Has anyone that you ever asked for help ever reported what you shared to an official or authority figure?"
The survey included closed- and open-ended follow-up questions about each type of MR experience. The CBLC and Hotline focused the survey on these three MR experiences based on the experiential evidence from their respective work with DV survivors and advocates. For example, the survey asked about receiving warnings because the CBLC learned from young people that when seeking help from people like teachers or social workers, young people were often warned that the person was mandated to report them if they continued sharing details about violence they experienced or witnessed. To avoid potential confusion or bias, the survey did not use the term "mandatory reporting." To further ensure clarity, most quantitative questions included an option for "I don't understand the question."

Quantitative Data Collection Close-ended questions on the survey included the three main questions above as well as the following questions: 4) "Did their warning change what you decided to share with them?" and 5) "Did their report make the situation better or worse?" Answer choices for most of the close-ended questions included "Yes," "No," and "I don't understand the question." The last question used a 5-point Likert scale ranging from "Much Worse" to "Much Better"

Qualitative Data Collection Open-ended questions on the survey included 6) "Who were you afraid to talk to?", 7) "What did you fear would happen if they reported the information?", 8) "Who gave you this warning?", 9) "Who did they say they would have to report the information to?", 10) "Please tell us how this changed what you decided to share with them.", and 11) "Please tell us how the report made the situation better or worse."
Table 2 Chi-Square and Multivariate Logistic Regression Analysis of Predictors for Not Asking for Help

\begin{tabular}{|c|c|c|c|c|c|}
\hline \multirow[b]{2}{*}{ Predictors } & \multicolumn{3}{|c|}{$\chi^{2}$ Analysis } & \multicolumn{2}{|l|}{ Logistic Regression } \\
\hline & $x^{2}$ & $\mathrm{df}$ & \# Yes $(\%)$ & Odds Ratio $(n=2106)$ & $95 \% \mathrm{CI}$ \\
\hline Race/Ethnicity $(n=2148)$ & 6.03 & 4 & & & \\
\hline API & & & $45(32.6 \%)$ & 0.92 & {$[0.62,1.35]$} \\
\hline Black & & & $93(30.2 \%)$ & 0.79 & {$[0.60,1.05]$} \\
\hline Latinx & & & $125(37.7 \%)$ & 1.12 & {$[0.87,1.44]$} \\
\hline Multiracial & & & $49(40.2 \%)$ & 1.18 & {$[0.80,1.75]$} \\
\hline White & & & $443(35.5 \%)$ & - & - \\
\hline Sexual Orientation $(n=2250)$ & 1.81 & 3 & & & \\
\hline Bisexual & & & $69(39.9 \%)$ & 1.13 & {$[0.81,1.57]$} \\
\hline Gay/Lesbian & & & $30(34.9 \%)$ & 0.88 & {$[0.54,1.44]$} \\
\hline Sexually Fluid & & & $34(37.4 \%)$ & 1.05 & {$[0.65,1.70]$} \\
\hline Heterosexual/Straight & & & $665(35.0 \%)$ & - & - \\
\hline Gender Identity $(n=2269)$ & $27.79 * * *$ & 2 & & & \\
\hline Woman- & & & $734(36.8 \%)$ & 0.48 & {$[0.22,1.05]$} \\
\hline Man- & & & $53(21.7 \%)$ & $0.22 * * *$ & {$[0.10,0.50]$} \\
\hline TGNC & & & $18(56.3 \%)$ & - & - \\
\hline
\end{tabular}

$* p<.05, * * p<.01, * * * p<.001$. Note: Reference groups for odds ratios are White, TGNC, and Heterosexual participants 
Table 3 Chi-Square and Multivariate Logistic Regression Analysis of Predictors for Being Warned

\begin{tabular}{|c|c|c|c|c|c|}
\hline \multirow[b]{2}{*}{ Predictors } & \multicolumn{3}{|c|}{$\chi^{2}$ Analysis } & \multicolumn{2}{|l|}{ Logistic Regression } \\
\hline & $x^{2}$ & $\mathrm{df}$ & \# Yes $(\%)$ & Odds Ratio $(n=2076)$ & $95 \% \mathrm{CI}$ \\
\hline Race/Ethnicity $(n=2118)$ & $13.00 *$ & 4 & $13(10.0 \%)$ & & \\
\hline API & & & $37(12.5 \%)$ & 0.65 & {$[0.36,1.19]$} \\
\hline Black & & & $45(13.8 \%)$ & 0.79 & {$[0.54,1.16]$} \\
\hline Latinx & & & $30(24.2 \%)$ & 0.88 & {$[0.62,1.25]$} \\
\hline Multiracial & & & $195(15.7 \%)$ & 1.65 & {$[1.05,2.59]$} \\
\hline White & & & & - & - \\
\hline Sexual Orientation $(n=2208)$ & 5.69 & 3 & $36(20.6 \%)$ & & \\
\hline Bisexual & & & $11(13.6 \%)$ & 1.32 & {$[0.88,1.97]$} \\
\hline Gay/Lesbian & & & $18(19.8 \%)$ & 0.70 & {$[0.34,1.43]$} \\
\hline Sexually Fluid & & & $275(14.8 \%)$ & 1.23 & {$[0.68,2.23]$} \\
\hline Heterosexual/Straight & & & & - & - \\
\hline Gender Identity $(n=2227)$ & $16.23 * * *$ & 2 & $306(15.7 \%)$ & & \\
\hline Woman- & & & $23(9.5 \%)$ & $0.43 *$ & {$[0.19,0.98]$} \\
\hline Man- & & & $12(34.3 \%)$ & $0.25 * *$ & {$[0.10,0.64]$} \\
\hline TGNC & & & & - & - \\
\hline
\end{tabular}

$* p<.05, * * p<.01, * * * p<.001$. Note: Reference groups for odds ratios are White, TGNC, and Heterosexual participants

\section{Analytical Approach}

\section{Quantitative Data Analysis}

First, we ran descriptives to identify the overall frequency of survivors' experiences with mandatory reporting. We examined demographic group differences by conducting chi-square significance tests with race/ethnicity, gender, and sexual orientation as independent variables and the dichotomous mandatory reporting variables as dependent variables. We then used multivariate logistic regression to further examine group differences, regressing all three demographic predictor variables simultaneously in one block for each of the dependent variables. We assessed model fit for all logistic regression models using Hosmer and Lemeshow Test statistic, standardized residuals, Cook's distance, DFBeta, leverage values, multicollinearity tolerance, and VIF values (Field 2009). All logistic regression models met all criteria for goodness-of-fit. Finally, the analytic sample featured less than $5 \%$ of data missing for each independent and dependent variable. Since this level of missing data poses less risk for introducing systematic bias into the sample (Tabachnick and Fidell 2006), we used pairwise deletion for all logistic regressions.

\section{Qualitative Data Analysis}

We analyzed qualitative data using inductive content analysis because the data consisted of hundreds of brief answers to open-ended questions. This allowed for the quantification of coded responses and facilitated a process of moving from the specific to the general (Elo and Kyngäs 2008). We followed guidelines provided by Miles et al. (2014) on the use of first-, second-, and third-order coding. First-order codes captured foundational components of the data, and we then grouped these codes into categories via second-order coding. Finally, third-order coding involved developing themes that encompass second-order codes and directly link back to first-order codes (Miles et al. 2014).

The fourth author open-coded $100 \%$ of the data, $20 \%$ of which was double coded by the second author; this encompassed the first-order coding process (Miles et al. 2014). The second and fourth authors then met with the first to collectively reconcile the coding between the two coders, to conduct second order coding by categorizing the codes, and to establish a preliminary codebook. The fourth author then recoded all of the data with the codebook, $20 \%$ of which was again double coded by the second author. All coders met again to reconcile codes and refine the codebook, after which the fourth author re-coded data from one question for which the codebook changed. The entire research team then met to discuss key themes that arose throughout the data, which are discussed in depth in the results section.

Trustworthiness Throughout the coding process, the authors remained vigilant to not abstract codes beyond what the data could support, and we continuously interrogated whether the codebook adequately captured the complexity in the data. We also examined the interrater reliability at every step of the coding process, identifying areas of divergence between coders and making modifications to the 
codes and codebook to increase clarity and coding convergence. These processes involved extensive conversations between the authors. When uncertainties arose about whether nuances in the data would be lost through abstraction, the team referred back to the research questions to guide their decisions.

Structural Analysis Given the study's emphasis on intersectionality, and because we understand cultural and community differences in outcomes as driven by underlying systemic inequities, this paper emphasizes system-level themes and codes. These include themes and codes related to systems such as criminal legal, child welfare, housing and immigrations systems.

\section{Mixed Methods Analysis}

We utilized matrices (Miles et al. 2014) to explore what, if any, consistent differences emerged across the qualitative results by gender and race/ethnicity. We began with these two dimensions of identity as the logistic regressions did not reveal significant sexual orientation differences, and no existing literature suggests reasons to expect differences by sexual orientation. As a result, we prioritized using the gender and racial/ ethnic quantitative data to further explore the qualitative data for the current study. We examined the frequency of responses within established themes according to identity and then created a categorization matrix to visually represent the coded data which allowed us to identify major intersectional themes.

\section{Reflexivity Statement}

Reflexivity is a common practice in qualitative research; it involves researchers examining how their backgrounds may influence their analyses of the data (Creswell 2014). The authors are queer researchers of diverse ages and racial and ethnic backgrounds who have witnessed and experienced the harms of interventions by the State in response to domestic violence. They aim to use research as a tool for transformative community and systems change by interrogating how systems of power and oppression disparately affect multiply marginalized survivors through formal services and policies. They believe that systems of surveillance operated by the carceral state are disproportionately used to control communities who have histories of disempowerment, abuse, and oppression. Therefore, they analyze data with the desire to understand, document, and measure the influence of these systems on the abilities for marginalized communities to access supportive services. Since the authors are deeply attuned to the potentially harmful impacts of MR laws, they engaged in continuous reflection and conversation to examine how their backgrounds might influence their perceptions of the data, and they employed myriad techniques described above to establish trustworthiness.

\section{Results}

\section{Mandatory Reporting Affects Who Survivors Turn to for Support}

\section{Survivors Were Afraid to Ask for Help}

Quantitatively, $35 \%$ of participants said they did not ask at least one person for help because they feared their information would be reported to an official or an authority figure. As shown in Table 2, chi-square analysis revealed statistically significant effects of gender identity, $\chi^{2}(2, N=2269)=27.79, p<.001$, and logistic regressions showed that TGNC participants were 4.59 times more likely not to turn to someone for help compared to men- (odds ratio $=0.22, p<.001)$. Logistic regressions revealed no statistically significant differences by race, sexual orientation, or between TGNC and women- participants.

Qualitative analysis revealed that survivors most commonly did not ask for help from a family member or friend. Almost $29 \%$ of respondents said they did not ask a family member or friend for fear that person would be legally required to report them. Survivors also reported not turning to medical and mental health care providers $(27.5 \%)$, police $(8.6 \%)$, or community-based organizations (2.2\%). Of the 718 survivors who responded to the qualitative questions, $19.4 \%$ stated they did not turn to anyone at all for fear of being reported.

Survivors Feared Help Would Lead to Criminal Legal Involvement Qualitative analysis illustrated that the most common system-level fear was that asking for help from someone would result in the arrest of their partner or the general involvement of the criminal legal system. Participants from nearly all racial/ethnic and gender groups expressed this fear. For most, it was the fear of their partner "being arrested" or "going to jail." Many participants explained severe consequences that would result from their partner's arrest. These included fear of their abuser's retaliation ("he would go to jail and get out and kill me"), loss of family income ("my husband would be arrested, and he is our only income, we have no savings"), and loss of relationship ("he might go to jail and/ or divorce me"). One participant stated that the arrest of their partner would cause the loss of "everything I have."

Race/Ethnicity and Gender Differences in Fear of Criminal Legal Involvement Qualitative differences emerged across racial/ethnic and gender groups regarding participants' fear of arrest and criminal legal involvement. For both men- and women- across racial/ethnic categories, the vast majority feared their partner's arrest. However, the reverse was true 
for White TGNC survivors, most of whom feared their own arrest. Additionally, several White women- expressed concerns that the criminal-legal system would take action without their consent. For example, one participant said they feared "charge[s] would be pressed without my consent," and another who feared "my abuser would be arrested, and I wouldn't be prepared." This was not a concern expressed by other racial/ethnic or gender groups.

Survivors Feared Help Would Lead to Child Protective Services Involvement Qualitatively, participants' next most common system-related fear was CPS involvement and having their children taken away. This was a fear almost exclusively expressed by women-. Many women- expressed a fear that "I would lose my children." Some women- included a specific fear that child protective services would get involved, as demonstrated by a participant who explained, "My children would be removed by CPS from my care." Other times, the fear of losing children was conveyed through broad mention of having children "taken" or "removed." For example, one participant feared "that my children would be removed and I would be blamed for everything, or called crazy." Other participants explained how they feared that reaching out for help would lead their abusers to follow through on threats to exploit child welfare agencies and custody courts to punish them. One participant feared that their "husband would find out and punish us as promised over the years, and he will take [my child]... and I'll never see her again." We found no qualitative differences across racial/ethnic groups for this theme.

\section{Survivors Feared Help Would Lead to Homelessness} Qualitatively, a less commonly expressed system-related fear was of becoming homeless or experiencing housing instability. This fear, while reported by only $3.2 \%$ of the sample, represents a particularly severe consequence that survivors saw connected to reaching out for help. One participant worried that reaching out to someone for help would mean "I lose the last of what I have. The roof over my head." Another feared that they "would be homeless and the abuse would get worse. There's no way out." We found no major demographic differences across racial/ethnic or gender groups regarding the fear of becoming homeless.

Survivors Feared Help Would Lead to Deportation The final system-related fear that arose from qualitative analysis was that reaching out for help from someone would result in their or their partner's deportation. Similar to the fear of homelessness, only a small number of participants reported this fear; however, the severity of this consequence is noteworthy. As one survivor explained, they feared that "my child's father would be deported and my child [would] be father-less." People who reported concerns about deportation were mostly people of color, and they demonstrated a mix of concern that they or their partner would be deported. It should be noted that of the small sample of API men-, the only fear they reported in turning to someone for support was about deportation.

\section{Mandatory Reporting Affects the Help Survivors Received}

\section{Survivors Seeking Help Receive Warnings}

Quantitative results demonstrated that $15.2 \%$ of survivors said that while seeking help, they were warned that the person they were talking to would have to report what they shared to an official or an authority figure. The odds of being warned differed significantly by race/ethnicity and gender. As shown in Table 3, chi-square analysis revealed statistically significant effects of race/ethnicity $\chi^{2}(4, N=2118)=13.79, p<.05$, and gender identity, $\chi^{2}(2, N=2227)=16.23, p<.001$. Logistic regressions showed that while seeking help, multiracial survivors were $64.9 \%$ more likely than White survivors to be warned that what they share may have to be reported (odds ratio $=1.65, p<.05)$. No other significant differences by race/ ethnicity emerged. In terms of gender, TGNC survivors were $57.2 \%$ more likely to be warned than women- (odds ratio = $0.43, p<.001)$ and $74.6 \%$ more likely than men- (odds ratio $=$ $0.25, p<.001)$. No significant differences by sexual orientation emerged.

Types of Help Sources Who Warned Survivors Qualitative analyses showed that for nearly half of respondents $(46.9 \%)$, the person who issued the warning was a mental or medical health provider. The next most common person to issue a warning was a family member or friend of the survivor. Just over a quarter of respondents (25.8\%) said that a family or friend warned them that they would legally have to report what the survivor shared to an official or an authority figure. In contrast, only $8.2 \%$ of respondents said they received warnings from a communitybased organization or social or case worker, and only $5.6 \%$ received a warning from a school official.

\section{MR Warnings Impact the Information Survivors Share} Quantitatively, of the 341 participants who were warned, $60.7 \%$ said the warning changed what they shared to the person who issued it. As shown in Table 4, chi-square and logistic regression analysis revealed no statistically significant differences by sexual orientation, gender identity, or race/ethnicity in the participants who changed what they shared versus those who did not. Qualitative responses revealed that for nearly a third of participants $(32.8 \%)$ who changed what they shared, the warning led them to withhold information and/or misrepresent their experiences. As one participant explains, "I did not disclose the most important problems, domestic violence and abuse." Another stated that they "left out any physical parts of 


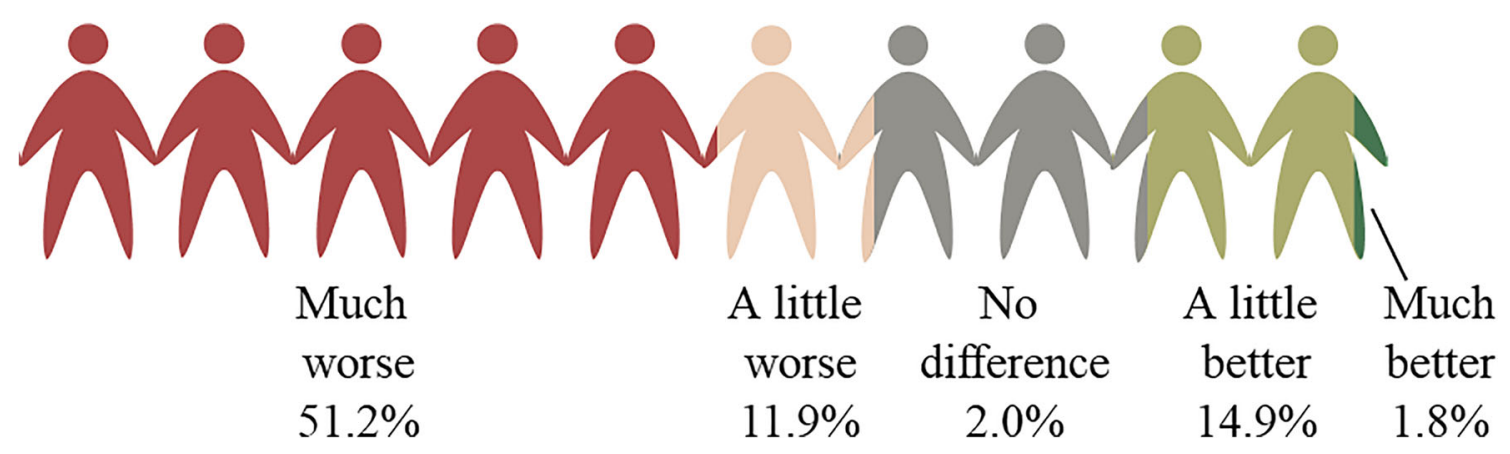

Fig. 1 Likert-scale responses for the impact of a mandatory report for 2322 respondents. Each person icon represents $10 \%$ of study participants

abuse towards children." Ultimately, the warning curtailed the ability of survivors to fully disclose and receive help based on the entirety of their experience.

MR Warnings Impact Willingness to Seek Help In addition to withholding information, qualitative data revealed that for another $22.7 \%$ of participants, the warning made them stop seeking help. Some participants did not seek help from the individual who issued the warning. Other participants explained that the warning made them stop seeking help altogether, as described by the participant who said, "I talk to no one, there's no one I can trust, no one I can turn to, and no where I can go." In these cases, the warnings isolated survivors and prevented them from seeking the support they need. In contrast, only a small minority of survivors $(2.5 \%)$ said that the warning prompted them to share everything and intentionally trigger a report. For one participant, the warning helped them "decide to finally report it."

\section{Survivors Seeking Help Trigger Mandatory Reports}

Quantitative data showed that when seeking help, $8.2 \%$ of respondents have had what they shared reported to an official or an authority figure. As shown in Table 5, chisquare and logistic regression analysis revealed no statistically significant differences by sexual orientation, gender identity, or race/ethnicity.

\section{Mandatory Reporting most Often Made the Situation Worse} Quantitative results demonstrated that when asked to report on a Likert scale whether the report made their situation better or worse, $51.2 \%$ of survivors said the report made the situation "much worse" compared to $1.8 \%$ that said it made the situation "much better" (Fig. 1). In total, $83.3 \%$ of survivors said the report either made the situation worse or had no impact. Outlined below, the qualitative responses describing the impact of the report revealed themes that match closely to what survivors feared
Table 4 Chi-Square and Multivariate Logistic Regression Analysis of Predictors for a Warning Changing What is Shared

\begin{tabular}{|c|c|c|c|c|c|}
\hline \multirow[b]{2}{*}{ Predictors } & \multicolumn{3}{|c|}{$\chi^{2}$ Analysis } & \multicolumn{2}{|l|}{ Logistic Regression } \\
\hline & $x^{2}$ & df & \# Yes $(\%)$ & Odds Ratio $(n=307)$ & $95 \% \mathrm{CI}$ \\
\hline Race/Ethnicity $(n=308)$ & 2.20 & 4 & & & \\
\hline API & & & $6(46.2 \%)$ & 0.56 & {$[0.18,1.75]$} \\
\hline Black & & & $20(57.1 \%)$ & 0.92 & {$[0.43,1.96]$} \\
\hline Latinx & & & $24(55.8 \%)$ & 0.79 & {$[0.40,1.56]$} \\
\hline Multiracial & & & $20(66.7 \%)$ & 1.48 & {$[0.62,3.53]$} \\
\hline White & & & $115(61.5 \%)$ & - & - \\
\hline Sexual Orientation $(n=325)$ & 2.42 & 3 & & & \\
\hline Bisexual & & & $24(68.6 \%)$ & 1.35 & {$[0.61,2.99]$} \\
\hline Gay/Lesbian & & & $5(45.5 \%)$ & 0.32 & {$[0.07,1.47]$} \\
\hline Sexually Fluid & & & $9(52.9 \%)$ & 0.56 & {$[0.17,1.84]$} \\
\hline Heterosexual/Straight & & & $160(61.1 \%)$ & - & - \\
\hline Gender Identity $(n=326)$ & 2.27 & 2 & & & \\
\hline Woman- & & & $182(61.9 \%)$ & 0.54 & {$[0.11,2.70]$} \\
\hline Man- & & & $9(45.0 \%)$ & 0.28 & {$[0.04,1.74]$} \\
\hline TGNC & & & $7(58.3 \%)$ & - & - \\
\hline
\end{tabular}

$* p<.05, * * p<.01, * * * p<.001$. Note: Reference groups for odds ratios are White, TGNC, and Heterosexual participants 
Table 5 Chi-Square and Multivariate Logistic Regression Analysis of Predictors for Being Reported

\begin{tabular}{|c|c|c|c|c|c|}
\hline \multirow[t]{2}{*}{ Predictors } & \multicolumn{3}{|c|}{$\chi^{2}$ Analysis } & \multicolumn{2}{|l|}{ Logistic Regression } \\
\hline & $x^{2}$ & $\mathrm{df}$ & \# Yes $(\%)$ & Odds Ratio $(n=1818)$ & $95 \% \mathrm{CI}$ \\
\hline Race/Ethnicity $(n=1857)$ & 7.37 & 4 & & & \\
\hline API & & & $7(5.9 \%)$ & 0.50 & {$[0.21,1.16]$} \\
\hline Black & & & $20(7.4 \%)$ & 0.63 & {$[0.37,1.05]$} \\
\hline Latinx & & & $24(8.2 \%)$ & 0.70 & {$[0.44,1.12]$} \\
\hline Multiracial & & & $15(14.2 \%)$ & 1.37 & {$[0.75,2.52]$} \\
\hline White & & & $111(10.4 \%)$ & - & - \\
\hline Sexual Orientation $(n=1940)$ & $9.57 *$ & 3 & & & \\
\hline Bisexual & & & $13(8.8 \%)$ & 0.76 & {$[0.41,1.43]$} \\
\hline Gay/Lesbian & & & $0(0.0 \%)$ & 0.00 & {$[0.00,0.00]$} \\
\hline Sexually Fluid & & & $11(13.8 \%)$ & 1.27 & {$[0.60,2.72]$} \\
\hline Heterosexual/Straight & & & $161(9.8 \%)$ & - & - \\
\hline Gender Identity $(n=1958)$ & $11.58 * *$ & 2 & & & \\
\hline Woman- & & & $179(10.4 \%)$ & 0.79 & {$[0.16,3.88]$} \\
\hline Man- & & & $7(3.3 \%)$ & 0.26 & {$[0.04,1.49]$} \\
\hline TGNC & & & $3(14.3 \%)$ & - & - \\
\hline
\end{tabular}

${ }^{*} p<.05,{ }^{*} p<.01, * * * p<.001$. Note: Reference groups are White, TGNC, and Heterosexual participants would happen if they reached out for help: involvement with the criminal legal system and removal of their children.

\section{MR Resulted in Negative Outcomes with Criminal Legal} System Qualitative analysis revealed that for the vast majority of participants, their experience with the criminal legal system through the mandatory reporting process was negative. Many survivors described how police involvement angered their partner and worsened the abuse they experienced. "Getting cops involved made him even more mad, and every time cops got involved, they never arrested him for it...so now he keeps coming after me knowing he gets away with it." Another survivor described how "things got bad when he found out police were involved."

Other survivors provided examples of the limited utility of criminal-legal involvement. Several described the lack of enforcement of protective orders, including one participant who described how when they report protection order violations, "an officer comes to my house but nothing is done." Others discussed the limited utility of incarceration. As one participant described, "The only difference was he went to jail one night and came home the next day." For still more, the court systems proved of little value. One participant described how their partner "was arrested, and the case was dismissed for lack of evidence, but no police officer or DA contacted me." Another explained how seeking help from an advocate led to the forced disclosure to a District Attorney who exacerbated the situation.

I thought what I was saying to the victims' advocate was confidential unless I gave permission. After our session, she said she had to give some of the info over to the DA.
The DA was going for a much more severe consequence when I wanted a different type of help for my abuser not a long-term incarceration or more DV/anger management classes that he could BS his way through or prison which wasn't the help he needed. I didn't trust anyone again in this type of position.

\section{Race/Ethnicity and Gender Differences in Involvement of the} Criminal Legal System Although the vast majority of womenacross all racial/ethnic groups qualitatively described their involvement with the criminal-legal system as negative, White women- were the only group to describe any positive interactions. For example, the police drove one White woman- to the hospital. For another, their interaction with police helped them realize that their "situation was more serious than I thought." Further, only White women- explained that the involvement of the criminal-legal system led to the incarceration of their abusive partner. For most, incarceration of their partner was not the outcome they wanted. One participant described how their partner was "in jail and he shouldn't be, and it's going to ruin our relationship for good." For others, their partner's incarceration posed problems for the future. One survivor explained, "He is in jail, but what happens when he gets out?" Another described how the arrest of their partner "started an entire series of problems that I haven't been able to escape from." For some, they did not perceive the incarceration of their partner as even increasing their immediate safety. "My ex is in jail, but I don't feel safe at my place."

No women- of color reported that criminal legal system involvement led to their partner's incarceration. Instead, 
women- of color reported that the involvement of the criminal legal system resulted in no change to their situation, retaliatory abuse, and/or their own arrest. In summary, although both White women- and women- of color primarily experienced negative responses by the criminal legal system, they experienced different kinds of negative responses, and if anyone had positive experiences, it was White women-.

MR Resulted in Children Being Removed from their Homes Qualitatively, survivors described the involvement of CPS, much like the criminal-legal system, as primarily a negative experience. Most survivors described severe consequences of CPS involvement, primarily the removal of their children from their care and home. One survivor explained how "CPS was brought in, and my kids were taken away and that was almost life ending." Another survivor illustrates the challenge of CPS involvement in cases of domestic violence, explaining that " $[t]$ hey removed my children from my home and charged me with allowing domestic violence to happen to me." This survivor may be referencing the aforementioned MR laws that identify child witnessing of domestic violence as a form of child abuse and neglect.

\section{Race/Ethnicity and Gender Differences in Involvement with}

Child Protective Services Although a smaller sample, most women- of color qualitatively described how their children were removed from their home because of CPS involvement. Some White women- also described this outcome; however, more White women- described negative consequences like the ineffectiveness of CPS, retaliatory abuse from their partner because of CPS involvement, or their children staying with other family until a CPS report was complete. One White woman- even described CPS helping to keep them and their children safe by monitoring their abuser.

Overall, CPS involvement and the removal of children was not a theme that emerged for men- or TGNC survivors. In fact, only one man- described CPS or removal of a child as an impact of a mandatory report.

Child Protective Services got involved back in May and now they've found my wife to be substantiated in the case.... I'm now with my parents and have my son with me but I am not sure now where to turn to get assistance for our own living arrangements and further assistance to protect my son.

Interestingly, this White man- described the most positive outcome of CPS out of the entire sample. They kept custody of their children, the abuse against their ex was substantiated, and they have been living with other family, awaiting additional supports. Although this represents a potentially bestcase scenario, even this survivor rated the impact of the report to have made the situation much worse, and they described needing additional supports to get their needs met.

\section{Discussion}

This mixed methods study aimed to understand how Mandatory Reporting (MR) laws influenced the helpseeking behaviors of a diverse group of IPV survivors who sought support from the Hotline. Previous studies found that survivors' experiences with and perceptions of mandatory reporting were mixed (Jordan and Pritchard 2018; Antle et al. 2010). Some studies also pointed to potential disparities in outcomes for survivors based on factors such as their race/ ethnicity (Dosanjh et al. 2008). Findings from the current study support, challenge, and expand the existing literature, illustrating numerous unintended harms of MR laws on the ability of all survivors to seek and receive the supports they need. MR laws negatively impacted survivors' access to resources, friends, family, and even safety. Survivors who were TGNC, people of color, and women- demonstrated important differences in their experiences with MR laws compared to survivors who were White and men-.

\section{Help-Seeking}

Similar to previous studies, the current study found that MR laws create barriers for survivors seeking supports (Jordan and Pritchard 2018; Goodman et al. 2019). Over a third of survivors in the sample - regardless of gender, race/ethnicity, and sexual orientation - did not turn to a potential support for fear related to MR. Participants described how they primarily feared people in their informal networks. No prior studies examined how MR laws affect survivors' help-seeking from their informal networks; however, the current study suggests that these laws negatively affect the perceived availability of informal networks for support. This perception is likely strengthened by the finding that of the survivors who were warned, over a quarter were warned by family or friends. These findings may reflect the fact that in over a third of U.S. states, all adults are mandated reporters (Child Welfare Information Gateway 2016a). Alternatively, some evidence suggests that it could also demonstrate a broader lack of understanding about MR laws and protocols, even among those who have received training (Perez-Darby et al. 2015). Given that informal social networks are often the first and most viable form of sustainable support for survivors (Sylaska and Edwards 2014), future research should explore the impact of MR laws that turn all adults in the state into mandatory reporters. Additional research should explore how to increase broader public knowledge about MR laws to ensure that survivors and support providers know who is and is not mandated to report and what they a required to report. 
Intersectional analyses revealed that when compared to men-, TGNC survivors were less likely to turn to someone for support and more likely to fear their own arrest. Research illustrates the consistent mistreatment and over-arrest of transgender community members by law enforcement (Stotzer 2014), which could explain TGNC survivors' fears and reluctance to reach out for help. Relatedly, mostly women- did not seek help for fear of involvement of CPS. This aligns with cultural norms and expectations of mothers as primary caretakers as well as studies revealing that mothers often receive greater scrutiny from CPS than even their abusive partners (Douglas and Walsh 2010). Finally, mostly people of color, and particularly API men-, expressed fears about deportation. This could reflect the current anti-immigration rhetoric in the U.S. that remains rooted in racism (Oppenheimer et al. 2016).

Based on their experiential knowledge, the community partners who designed the study included an aspect of MR not previously explored in the literature: warnings made by providers about MR. The partners knew that many providers, in an attempt to prevent triggering a report, warn the person seeking help that they might have to report. By and large, the current study finds that these warnings hindered the ability of survivors to receive the support they sought. Upon receiving the warnings, most survivors qualify and change what they share, which in some ways is the intended goal of the warning. However, doing so meant survivors leave out important details about their experiences and some stop seeking help altogether. While these strategies may protect survivors from triggering reports, they also serve as obstacles to receiving help and can increase survivors' isolation. Future research should work with IPV advocates and survivors to identify other ways that MR laws may affect survivors even when a report is not triggered.

Intersectional analyses showed that Multiracial and TGNC survivors were more likely to be warned compared to White survivors and survivors of other gender groups, respectively. This may relate to the unique forms of prejudice and pathologizing that both groups receive broadly in U.S. culture, including assumptions by others that they are psychologically abnormal or bizarre (Nadal et al. 2011; Nadal et al. 2010). This expectation and the continued literal pathologizing of transgender people (American Psychiatric Association 2013) may also explain why the study found TGNC survivors were significantly more likely to be reported compared to people of other genders.

\section{Impact of Reports}

The majority of survivors who were reported stated that the report worsened their situation, often by involving them in systems they deemed unhelpful at best or harmful at worst. Survivors' interactions with these systems, chiefly criminal- legal and child protection systems, often increased the abuse they experienced and compromised their financial, housing, and family stability. Only about $17 \%$ of survivors said the report made their situation any better. A few reasons may explain why these findings contrast with other research showing survivors having greater ambivalence about MR laws. The first is that this study explores MR laws across a diversity of settings and states, not just in healthcare settings (Coulter and Chez 1997; Gielen et al. 2000) or in the state of Kentucky (Jordan and Pritchard 2018; Antle et al. 2010). Findings from the current study suggest implementation of MR laws vary greatly, so capturing a wider breadth of experiences may mean the current study illustrates more extensive challenges with the laws. Additionally, the current study examines survivors' direct experiences with MR laws, rather than abstract opinions about them (Coulter and Chez 1997).

Intersectional analyses revealed that although the majority of all women- rated the impact of reports negatively, racial/ ethnic differences emerged in the type of negative impacts women- experienced. For example, police involvement for women- of color did not result in arrest of their partner whereas it did for several White women-. Similarly, CPS involvement for women- of color more often resulted in the loss of their children than for White women-. Many argue that cultural notions of vulnerability and victimhood center the experience of White women and are influenced by racist stereotypes of many communities of color, including that Black women are too aggressive and thus cannot be victims (Sokoloff and Pratt 2005). This could partially explain the differential police responses. Further, national research shows disproportionally higher rates of foster care placements for Native, African American, and, for some states, Latinx children compared to White children (Hill 2007), which could support the different racial impacts of CPS. Again, the majority of both groups of women- rated the responses they received from law enforcement and CPS negatively, so future research is needed to explore the kinds of system responses to a mandatory report that survivors see as beneficial.

\section{Policy \& Practice Implications}

This study has specific implications for both policy and IPV practice. First, having more people be defined as a mandated reporter can isolate survivors and reduce access to their informal networks. Advocates and policymakers should thus examine MR laws with an eye to maximizing opportunities for survivors to seek help without triggering unwanted reports. Second, warnings from providers about MR laws reduce help-seeking efforts for most survivors. IPV programs should reexamine agency policies that encourage this disclosure and identify alternative ways to reduce the risk of triggering reports, including by understanding the exact requirements and exceptions for reporting in their state. Third, policymakers and 
the antiviolence field must deeply reflect on the cost-benefit of MR laws. Protecting vulnerable populations remains as important today as when states first enacted MR laws decades ago. The current study demonstrates, however, that mandating the involvement of systems and institutions with long histories of harm is making the situation worse for many survivors and families. This highlights a need for identifying alternative strategies and solutions to protect and support vulnerable populations. There may be lessons from transformative and restorative justice approaches that focus on utilizing communitybased processes that exist outside of the criminal legal system to address harms, ensure accountability, and prevent future harms (Creative Interventions 2012; Goodmark 2018). The antiviolence field could benefit from examining ways to design and implement these alternative approaches in cases that are currently being addressed by MR laws.

\section{Limitations}

Several limitations to the study should be considered. First, partnering with the Hotline required that we prioritize service provision while collecting data, which limited the number of questions we could ask, including around demographic information. Second, we studied help-seeking practices in a sample who was already seeking help from an IPV hotline, which may impact the generalizability of the findings. Third, we did not independently assess if the person who contacted the Hotline was a person causing or experiencing harm; however, understanding barriers for both members to access support is important. Given the complicated roles and names for mandatory reporters across the nation, we did not ask about mandatory reporting specifically by name. The proxy descriptors we used drew on the expertise of the project's partners, including a national IPV technical assistance provider and the largest DV service provider in the country. Some survivors might have misunderstood the proxy descriptors. By including "I don't understand the question" options, we hopefully mitigated the propensity for some participants to complete the questions if they did not understand them. Additionally, although the overall sample size for the study was large, some of the subgroup sizes when looking differentially across demographic groups were small. This may weaken some of the generalizability of our study. Finally, the low response rate for the survey may further restrict the generalizability; however, analytic comparisons found only small demographic differences between those who did and did not complete the survey.

This study was the first of its kind to use a national sample inclusive of LGBTQ and racially and ethnically diverse survivors to explore the impacts of MR laws on the help-seeking of IPV survivors. The study findings indicate an ongoing need to attend to the real harms of MR laws to increase all survivors' ability to successfully seek and receive the support they need.
Acknowledgments This research was made possible by Grant Numbers 90EV0432 and 90EV0433 from Administration of Children, Youth and Families, Family and Youth Services Bureau, U.S. Department of Health and Human Services. The opinions, findings, conclusions and recommendations expressed in this publication are those of the author(s) and do not necessarily reflect the views of the Administration on Children, Youth and Families, Family and Youth Services Bureau, U.S. Department of Health and Human Services.

Thanks to the National Domestic Violence Hotline for supporting this study. Thanks also to Maryclare Griffin for cleaning and screening the initial database and Chris Harper for data analysis consultation.

Open Access This article is distributed under the terms of the Creative Commons Attribution 4.0 International License (http:// creativecommons.org/licenses/by/4.0/), which permits unrestricted use, distribution, and reproduction in any medium, provided you give appropriate credit to the original author(s) and the source, provide a link to the Creative Commons license, and indicate if changes were made.

\section{References}

Ahrens, C. E., Rios-Mandel, L. C., Isas, L., \& del Carmen Lopez, M. (2010). Talking about interpersonal violence: Cultural influences on Latinas' identification and disclosure of sexual assault and intimate partner violence. Psychological Trauma: Theory, Research, Practice, and Policy, 2(4), 284. https://doi.org/10.1037/a0018605.

American Psychiatric Association. (2013). Diagnostic and statistical manual of mental disorders (5th ed.). Washington, DC: Author.

Antle, B., Barbee, A., Yankeelov, P., \& Bledsoe, L. (2010). A qualitative evaluation of the effects of mandatory reporting of domestic violence on victims and their children. Journal of Family Social Work, 13(1), 56-73. https://doi.org/10.1080/10522150903468065.

Breiding, M. J., Chen, J., \& Black, M. C. (2014). Intimate partner violence in the United States - 2010. Atlanta, GA: National Center for Injury Prevention and Control, Centers for Disease Control and Prevention.

Calton, J. M., Cattaneo, L. B., \& Gebhard, K. T. (2016). Barriers to help seeking for lesbian, gay, bisexual, transgender, and queer survivors of intimate partner violence. Trauma, Violence, \& Abuse, 17(5), 585-600. https://doi.org/10.1177/1524838015585318.

Child Welfare Information Gateway. (2016a). Mandatory reporters of child abuse and neglect. Washington, DC: U.S. Department of Health and Human Services, Children's Bureau.

Child Welfare Information Gateway. (2016b). Child witnesses to domestic violence. Washington, DC: U.S. Department of Health and Human Services, Children's Bureau.

Collins, P. H., \& Bilge, S. (2016). Intersectionality in. Malden, MA: Polity Press.

Coulter, M. L., \& Chez, R. A. (1997). Domestic violence victims support mandatory reporting: For others. Journal of Family Violence, 12(3), 349-356.

Creative Interventions (2012). Creative Interventions toolkit: A practical guide to stop interpersonal violence. Retrieved from www.creativeinterventions.org.

Creswell, J. W. (2014). A concise introduction to mixed methods research. Thousand Oaks, CA: SAGE Publications, Inc..

Deutsch, L. S., Resch, K., Barber, T., Zuckerman, Y., Stone, J. T., \& Cerulli, C. (2017). Bruise documentation, race and barriers to seeking legal relief for intimate partner violence survivors: A retrospective qualitative study. Journal of Family Violence, 32(8), 767-773. https://doi.org/10.1007/s10896-017-9917-4.

DeVoe, E. R., \& Smith, E. L. (2003). Don't take my kids: Barriers to service delivery for battered mothers and their young children. 
Journal of Emotional Abuse, 3(3-4), 277-294. https://doi.org/10. 1300/J135v03n03_06.

Dill, B. T., \& Zambrana, R. E. (2009). Critical thinking about inequality: An emerging lens. In B. T. Dill \& R. E. Zambrana (Eds.), Emerging intersections: Race, class, and gender in theory, policy, and practice. New Brunswick: Rutgers University Press.

Dosanjh, S., Lewis, G., Mathews, D., \& Bhandari, M. (2008). Child protection involvement and victims of intimate partner violence: Is there a bias? Violence Against Women, 14(7), 833-843. https://doi. org $/ 10.1177 / 1077801208320247$.

Douglas, H., \& Walsh, T. (2010). Mothers, domestic violence, and child protection. Violence Against Women, 16(5), 489-508. https://doi. org/10.1177/1077801210365887.

Durborow, N., Lizdas, K. C., O'Flaherty, A., \& Marjavi, A. (2013). Compendium of state statutes and policies on DV and health care. Family Violence Prevention Fund.

Elo, S., \& Kyngäs, H. (2008). The qualitative content analysis process. Journal of Advanced Nursing, 62(1), 107-115. https://doi.org/10. $1111 / j .1365-2648.2007 .04569 . x$.

Fauci, J. E., \& Goodman, L. A. (2019). "You don't need nobody else knocking you down": Survivor-mothers' experiences of surveillance in domestic violence shelters. Journal of Family Violence, 114. https://doi.org/10.1007/s10896-019-00090-y.

Field, A. (2009). Discovering statistics using SPSS. Thousand Oaks, CA: SAGE Publications.

Gielen, A. C., O'Campo, P. J., Campbell, J. C., Schollenberger, J., Woods, A. B., Jones, A. S., et al. (2000). Women's opinions about domestic violence screening and mandatory reporting. American Journal of Preventive Medicine, 19(4), 279-285.

Girardet, R., Lahoti, S., Bolton, K., \& Kellogg, N. (2016). Characteristics of cases submitted to a statewide system of child abuse experts. Children and Youth Services Review, 67, 198-202. https://doi.org/ 10.1016/j.childyouth.2016.06.007.

Goodman, L. A., Fauci, J. E., Hailes, H. P., \& Gonzalez, L. (2019). Power with and power over: Domestic violence advocates manage their roles as mandated reporters. Journal of Family Violence., 1-15. https://doi.org/10.1007/s10896-019-00040-8.

Goodmark, L. (2018). Decriminalizing domestic violence: A balanced policy approach to intimate partner violence. Oakland, CA: University of California Press.

Hill, R. B. (2007). An analysis of racial/ethnic disproportionality and disparity at the national, state, and county levels. Paper presented at the Casey-CSSP Alliance for Racial Equity in the Child Welfare System.

Hirschel, D., Buzawa, E., Pattavina, A., Faggiani, D., \& Reuland, M. (2007). Explaining the prevalence, context, and consequences of dual arrest in intimate partner cases Retrieved from U.S. Department of Justice: https://www.ncjrs.gov/pdffiles1/nij/grants/ 218355.pdf.

Jordan, C. E., \& Pritchard, A. J. (2018). Mandatory reporting of domestic violence: What do abuse survivors think and what variables influence those opinions? Journal of Interpersonal Violence. https://doi. org $/ 10.1177 / 0886260518787206$.

Kanuha, V. K. (2005). Compounding the triple jeopardy: Battering in lesbian of color relationships. In N. J. Sokoloff \& C. Pratt (Eds.), Domestic violence at the margins: Readings on race, class, gender, and culture. New Brunswick: Rutgers University Press.

Langenderfer-Magruder, L., Whitfield, D. L., Walls, N. E., Kattari, S. K., \& Ramos, D. (2016). Experiences of intimate partner violence and subsequent police reporting among LGBTQ adults in Colorado: Comparing rates of cisgender and transgender victimization. Journal of Interpersonal Violence, 31(5), 855-871. https://doi.org/ $10.1177 / 0886260514556767$.
Lippy, C., Burk, C., \& Hobart, M. (2016). There's no one I can trust: The impact of mandatory reporting on the help-seeking and well-being of domestic violence survivors. Seattle, WA: National LGBTQ DV Capacity Building Learning Center.

Miles, M. B., Huberman, A. M., \& Saldaña, J. (2014). Qualitative data analysis: A methods sourcebook. In (3rd ed.). Thousand Oaks, CA: SAGE Publications, Inc..

Nadal, K. L., Rivera, D. P., \& Corpus, M. J. H. (2010). Sexual orientation and transgender microaggressions: Implications for mental health and counseling. In D. W. Sue (Ed.), Microaggressions \& marginality: Manifestations, dynamics and impact. Hoboken, NJ: John Wiley \& Sons.

Nadal, K. L., Wong, Y., Griffin, K., Sriken, J., Vargas, V., Wideman, M., \& Kolawole, A. (2011). Microaggressions and the multiracial experience. International Journal of Humanities and Social Science, $1(7), 36-44$.

Ogbonnaya, I. N., \& Pohle, C. (2013). Case outcomes of child welfareinvolved families affected by domestic violence: A review of the literature. Children and Youth Services Review, 35(9), 1400-1407. https://doi.org/10.1016/j.childyouth.2013.05.014.

Oppenheimer, D. B., Prakash, S., \& Burns, R. (2016). Playing the trump card: The enduring legacy of racism in immigration law. Berkeley $L a$ Raza Law Journal 26 1-45. https://doi.org/10.15779/Z38TG3V.

Perez-Darby, S., Lippy, C., Mendoza, B., Burk, C. (2015). Queer collaborations: Full spectrum support for LGBTQ youth. Report submitted to Office of Violence Against Women.

Richie, B. (2012). Arrested justice: Black women, violence, and America's prison nation. New York: New York University Press.

Smith, S. G., Zhang, X., Basile, K. C., Merrick, M. T., Wang, J., Kresnow, M., \& Chen, J. (2018). The national intimate partner and sexual violence survey (NISVS): 2015 data brief - Updated release. In. Atlanta, GA: National Center for Injury Prevention and Control, Centers for Disease Control and Prevention.

Sokoloff, N. J., \& Pratt, C. E. (2005). Domestic violence at the margins: Readings on race, class, gender, and culture. Rutgers University Press.

Stotzer, R. L. (2014). Law enforcement and criminal justice personnel interactions with transgender people in the United States: A literature review. Aggression and Violence Behavior, 19(3), 263-277. https://doi.org/10.1016/j.avb.2014.04.012.

Sullivan, C. M., \& Hagen, L. A. (2005). Survivors' opinions about mandatory reporting of domestic violence and sexual assault by medical professionals. Affilia, 20(3), 346-361. https://doi.org/10.1177/ 0886109905277611.

Sylaska, K. M., \& Edwards, K. M. (2014). Disclosure of intimate partner violence to informal social support network members: A review of the literature. Trauma, Violence, \& Abuse, 15(1), 3-21. https://doi. org $/ 10.1177 / 1524838013496335$.

Tabachnick, B. G., \& Fidell, L. S. (2006). Using multivariate statistics (5th ed.). Nedham Heights, MA: Allyn \& Bacon.

Trotter, J. L., \& Allen, N. E. (2009). The good, the bad, and the ugly: Domestic violence survivors' experiences with their informal social networks. American Journal of Community Psychology, 43(3-4), 221-231. https://doi.org/10.1007/s10464-009-9232-1.

Walters, M. L., Chen, J., \& Breiding, M. J. (2013). The national intimate partner and sexual violence survey (NISVS): 2010 findings on victimization by sexual orientation. Atlanta, GA: National Center for Injury Prevention and Control, CDC.

Publisher's Note Springer Nature remains neutral with regard to jurisdictional claims in published maps and institutional affiliations. 